\title{
Comparative study of Candida in oral submucous fibrosis and healthy individuals
}

\section{Estudo comparativo de Candida em fibrose submucosa oral e indivíduos saudáveis}

\begin{abstract}
Purpose: Oral submucous fibrosis (OSMF) is a high-risk precancerous condition that predominantly affects Indian youngsters due to the habit of gutkha chewing. Candida may play a role in the etiopathogenesis of premalignant and malignant lesions. The aim of this study is to compare the incidence, intensity, and species of Candida found in OSMF patients and healthy individuals.

Methods: This study included 20 OSMF patients and 20 healthy controls. A detailed history of each patient was recorded along with a clinical examination. Samples were collected with the oral rinse technique and cultured on Sabouraud's agar medium. The isolated yeast species were counted and identified based on Gram staining, a germ tube test, chlamydospore formation and a sugar assimilation test.

Results: In total, $40 \%$ of OSMF patients and $15 \%$ of healthy controls yielded Candida organisms on culture. C. albicans was the predominant species isolated, but C. krusei and C. tropicalis were also identified. Gender, gutkha habit and clinical staging had no influence on the candidal carriage in OSMF patients.

Conclusion: The incidence and intensity of Candida (primarily C. albicans) was greater in OSMF patients than in healthy controls, but these findings were within the normal limit (3-47\%). Therefore, Candida may not be an etiologic factor in malignant transformation. However, controversy still exists over whether the chewing of betel quid in cases of OSMF has an inhibitory effect or promotes the adherence and invasion of Candida.
\end{abstract}

Key words: Candida; gutkha chewing; oral carriage; oral submucous fibrosis

\section{Resumo}

Objetivo: Fibrose submucosa oral (FSO) é uma condição pré-maligna de alto risco que predominantemente afeta jovens da Índia devido ao hábito de mascar 'gutkha'. Candida pode ter um papel importante na etiopatogenia de lesões pré-malignas e malignas. $\bigcirc$ objetivo deste estudo foi comparar a incidência, intensidade e Candida spp encontradas em pacientes com FSO e em indivíduos saudáveis.

Metodologia: Este estudo incluiu 20 pacientes com FSO e 20 controles saudáveis. Obteve-se de cada sujeito uma história detalhada e exame clínico. As amostras foram coletadas com uma técnica de enxágue bucal e cultivadas em meio Agar Sabouraud. As espécies isoladas foram contadas e identificadas com base em coloração Gram, teste de tubo de ensaio e teste de assimilação de açúcar.

Resultados: No total, 40\% dos pacientes com FSO e 15\% dos controles saudáveis apresentaram resultado positivo de cultura para Candida. C. albicans foi a espécie predominante isolada mas C. krusei e C. tropicalis também foram identificados. O sexo, hábito de mascar 'gutkha' e estadiamento clínico não influenciaram a presença de fungos nos pacientes com FSO.

Conclusão: A incidência e intensidade de Candida (primariamente C. albicans) foi maior nos pacientes com FSO que nos sujeitos controle, mas estes achados estavam dentro dos limites normais (3-47\%). Portanto, Candida pode não ser um fator etiológico na transformação maligna. Entretanto, ainda há controvérsias se o hábito de mascar 'betel' em casos de FSO teria um efeito inibidor ou promoveria a aderência e invasão de Candida.

Palavras-chave: Candida; gutkha; fibrose submucosa oral

\section{K Anila a \\ Kaveri Hallikeri a \\ Shubhada C b \\ Naikmasur VG \\ R D Kulkarni b}

a Department of Oral and Maxillofacial Pathology, S.D.M College of Medical Sciences \& Hospital, Dharwad, Karnataka, India

${ }^{b}$ Department of Microbiology, S.D.M College of Medical Sciences \& Hospital, Dharwad, Karnataka, India

cDepartment of Oral Medicine and Radiology, S.D.M College of Medical Sciences \& Hospital, Dharwad, Karnataka, India

\author{
Correspondence: \\ Kaveri Hallikeri \\ Department of Oral and Maxillofacial Pathology \\ S.D.M. College of Dental sciences and Hospital \\ Dharwad - 580009, Karnataka - India \\ E-mail: drcauveri2005@gmail.com
}

Received: November 26, 2010

Accepted: February 14, 2011

Conflict of Interest Statement: The authors state that there are no financial and personal conflicts of interest that could have inappropriately influenced their work.

Copyright: (C) 2011 Anila et al.; licensee EDIPUCRS. This is an Open Access article distributed under the terms of the Creative Commons AttributionNoncommercial-No Derivative Works 3.0 Unported License. 


\section{Introduction}

Candida species cause common oral fungal infections in human beings (1). The presence of Candida in the mouth together with epithelial changes may predispose individuals to candidal infection (2). Epithelial changes of the oral mucosa, such as atrophy, hyperplasia, and dysplasia, may compromise the mucosal barrier and facilitate candidal invasion, especially in the event of epithelial atrophy (3).

Candida albicans is the primary cause of oral candidiasis. These opportunistic fungal pathogens may colonize, invade and induce lesions in any part of the oral cavity in both immunocompetent and immunocompromised individuals. However, those who are immunocompromised are affected at a significantly higher frequency than healthy individuals (4). As a result of increasing numbers of immunocompromised individuals within the human population, the incidence of Candida infections has increased dramatically in the last decade (5).

Cannon et al. have suggested that Candida colonization of oral surfaces, including the denture-fitting surface, can serve as a reservoir for disseminated infections such as aspirate pneumonia and gastrointestinal infections (6). C. albicans is the predominant species isolated in premalignancy and carcinoma. Candidal infection can induce epithelial atypia and lead to malignant transformation through the release of chemical carcinogens like nitrosamine compounds (2). Similarly, Candida could play a role in malignant transformation in OSMF, but this process has not been confirmed.

Recently, oral submucous fibrosis (OSMF) has been identified as a high-risk precancerous condition that affects young Indians due to their habit of gutkha chewing $(7,8)$. Several predisposing factors may be present in patients with OSMF, but epithelial atrophy is considered one of the key features of OSMF. Decreased mouth opening may predispose an individual to candidal growth, and this Candida can further predispose the mucosa for malignant transformation through the process of nitrosation $(2,9)$. The aim of the present study was to determine the incidence, intensity and species of Candida present in the oral cavity of oral submucous fibrosis patients and healthy controls.

\section{Methods}

The study included a total of 40 male and female participants. Patients were selected from among those visiting the outpatient department of oral medicine and radiology at SDM Dental College and Hospital in Dharwad. The study protocol was approved by the institutional ethics committee.

The study group included twenty cases of oral submucous fibrosis and twenty age- and gender-matched healthy controls. Informed consent was obtained from all participants prior to inclusion in the study. A detailed clinical history was obtained from each participant and clinical staging was noted using the criteria established by Ranganathan et al. (10). OSMF patients with systemic illnesses like diabetes were excluded from the study.

\section{Microbiology}

The oral rinse technique described by Samaranayake et al. (11) was used to collect samples. Subjects in both groups were asked to rinse their mouth with $10 \mathrm{~mL}$ of phosphate buffered saline (PBS) for $2 \mathrm{~min}$ and expectorate into a sterile container. The sample was immediately transported to the laboratory where it was centrifuged at 2,500 g for $10 \mathrm{~min}$. The pellet was resuspended in PBS; $100 \mu \mathrm{L}$ of this solution were plated onto Sabouraud's dextrose agar and incubated for $48 \mathrm{~h}$ at $37^{\circ} \mathrm{C}$. Colony forming units resembling yeast growth were removed from the plates and processed further for identification using Gram staining, a germ tube test, chlamydospore formation and sugar assimilation tests (3). The number of yeast colonies was counted and expressed as colony-forming units per milliliter $(\mathrm{CFU} / \mathrm{mL})$ of the collected sample. To facilitate the differentiation of $C$. albicans and C. dubliniensis, we investigated the growth at $45^{\circ} \mathrm{C}$ on modified Sabouraud glucose agar (SGA).

\section{Cytology}

Buccal smears were obtained from both groups and stained using the periodic acid schiff (PAS) technique. The stained smears were examined under a microscope (original magnification X40). The presence of Candida yeast cells or yeast cells and pseudohyphae was recorded as a positive finding and classified as follows: group $1=$ none, group 2 = yeast cells only, group $3=$ a few yeast cells and pseudohyphae (2-3 cells), and group $4=$ many yeast cells and pseudohyphae.

Statistical analysis

Group analyses were performed with the chi-square test and the differences between two independent samples were analyzed with the Student's $t$-test. A $P$-value $<0.05$ was considered statistically significant.

\section{Results}

The mean age of both groups was 26.7 years, and $90 \%$ of the participants were male. Of the 20 individuals with OSMF, 18 (90\%) chewed gutkha (areca nut and tobacco) and only $2(10 \%)$ chewed areca nut alone. The average mouth opening of patients with OSMF was $19.75 \mathrm{~mm}$.

In total, $40 \%(8 / 20)$ of the OSMF patients and $15 \%$ $(3 / 20)$ of the controls yielded Candida organisms on culture. However, the difference between the two groups was not statistically significant $\left(\mathrm{x}^{2}=3.135 ; P=0.770\right)$ (Table 1$)$.

Table 1. Presence of Candida in the OSMF and control groups.

\begin{tabular}{ccccc}
\hline Groups & $\begin{array}{c}\text { No. of } \\
\text { cases }\end{array}$ & $\begin{array}{c}\text { Frequency of } \\
\text { Candida isolation }\end{array}$ & $x^{2}$ & P-value* $^{*}$ \\
\hline Control Group & 20 & $3(15 \%)$ & 3.135 & 0.077 \\
OSMF Group & 20 & $(40 \%)$ & & \\
\hline
\end{tabular}

* Chi square test 
The mean counts of Candida colonies in the OSMF and control groups were $721.25 \mathrm{CFU} / \mathrm{mL}$ and 186.7 $\mathrm{CFU} / \mathrm{mL}$, respectively. However, the difference between the two groups was not statistically significant $(\mathrm{t}=5.6030$; $P=0.0053$ ) (Table 2).

Gender had no influence on the yeast carriage in the mouth $\left(\chi^{2}=0.0930, P=0.761\right)$ (Fig. 1). The habit of betel chewing (Fig. 2) and clinical staging (Fig. 3) had no influence on the candidal carriage status of OSMF patients. Cytological buccal smears detected no yeast cells or pseudohyphae in either group.
Three different candidal species were isolated from the OSMF group (C. albicans, $C$. krusei and C. tropicalis) and two species were isolated from the control group $(C$. albicans and C. tropicalis). Candida albicans was the most common isolate in OSMF patients $(n=7,87.5 \%)$, while Candida krusei (37.5\%) and Candida tropicalis (12.5\%) were less common (Fig. 4). In addition, two species were simultaneously present in three OSMF patients; C. albicans and $C$. krusei were present in two patients, and $C$. albicans and $C$. tropicalis were present in one patient.

Table 2. Intensity of Candida in the OSMF and control groups.

\begin{tabular}{lccccc}
\hline \multicolumn{1}{c}{ Group } & $\begin{array}{c}\text { Range } \\
\text { CFU } / \mathrm{mL}\end{array}$ & Mean CFU $/ \mathrm{mL}$ & SD & t-value & P-value* \\
\hline Control group & $60-320$ & 186.6667 & 130.1281 & -5.6030 & \multirow{2}{*}{0.0053} \\
OSMF group & $500-970$ & 721.2500 & 143.8687 & & \\
\hline
\end{tabular}

* Student's t-test
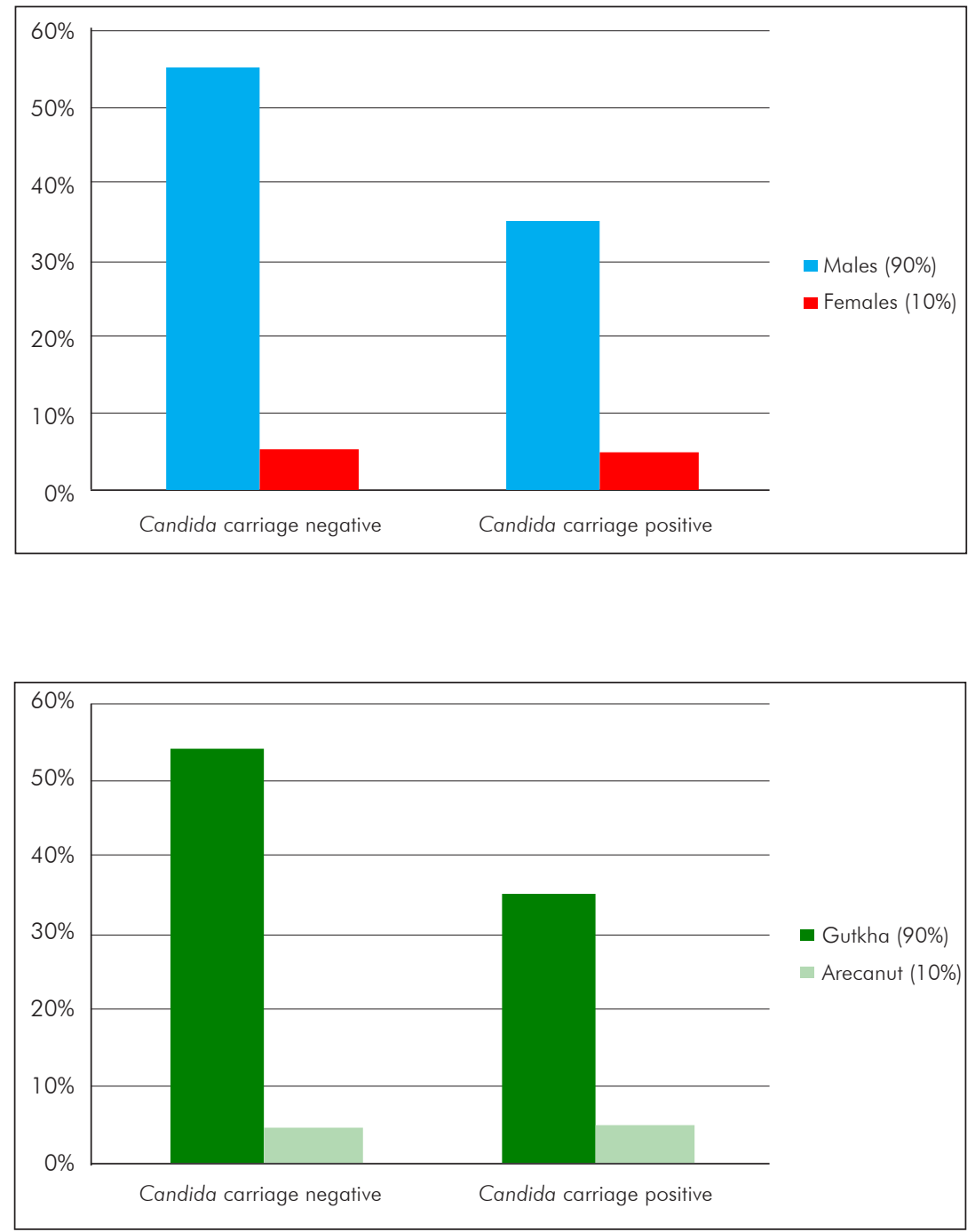

Fig. 1. Gender distribution and candidal carriage in patients with oral submucous fibrosis.
Fig. 2. Chewing habit and candidal carriage in patients with oral submucous fibrosis. 

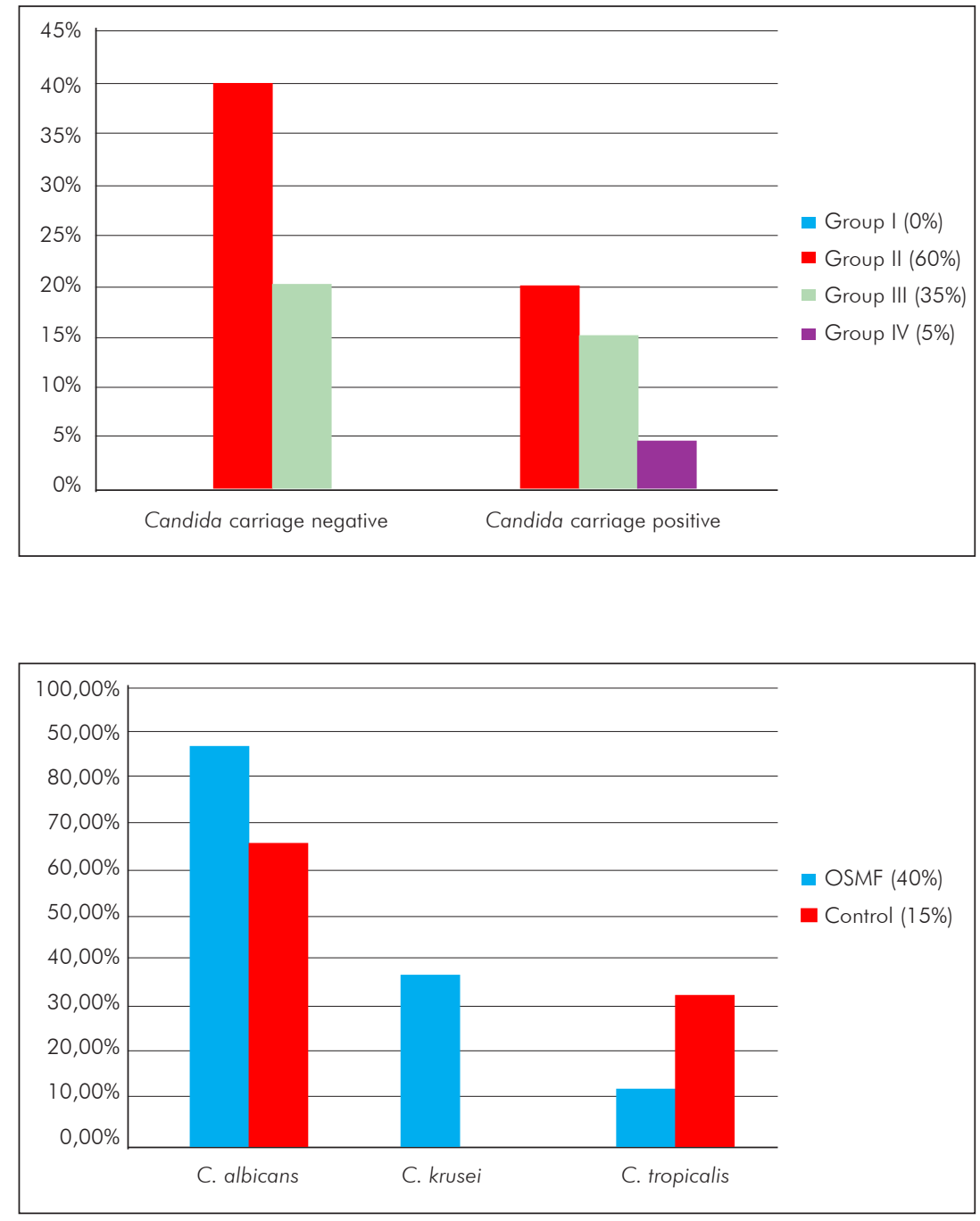

Fig. 3. Clinical staging and candidal carriage in patients with oral submucous fibrosis.
Fig. 4. Distribution of Candida species in OSMF and control group.

\section{Discussion}

Healthy individuals carry 3-47\% of Candida species as a component of normal oral flora (11). Oral yeasts are known to be associated with systemic and localized oral disease. The predominant species is Candida albicans, which has the potential to infect any tissue within the body (6). Other Candida species that have been isolated are C. krusei, C. guilliermondii and C. tropicalis (12).

An association between Candida and various precancerous and cancerous lesions has been reported in the literature (13-15). Candida has also been reported in cases of lichen planus, and its prevalence has increased in lichen planus patients undergoing topical steroid therapy (16).

Studies of various populations have recently linked the use of betel quid to the presence of candidal species. Reichart et al. has studied oral candidal species in betel quid chewers and identified associated oral lesions in Cambodian females. Candida albicans was the most commonly isolated species and $C$. tropicalis was the second most isolated species. A single isolate of the newly described C. dubliniensis was found in the control population (17).

In another study conducted in isolated populations of Padaung, C. parapsilosis was the most common Candida species isolated from both betel quid chewers $(46 \%)$ and non-chewers (44\%). Candida albicans was identified in $24 \%$ of betel quid chewers and $18 \%$ of non-chewers (18).

A study by Ariyawardana et al. sought to determine the prevalence of oral yeast in OSMF patients and healthy individuals. Candida was isolated from $63.6 \%$ of the test group and $50 \%$ of the control group. This study also reported $C$. dubliniensis for the first time in both groups (19). However, none of these studies revealed statistically significant differences in the prevalence of Candida species between the two groups.

Our study revealed a higher candidal prevalence in OSMF patients (40\%) when compared to a control group (15\%), and mean scores of candidal growth were also higher in OSMF patients than controls; however there was no statistically 
significant difference between the two groups. The results of the present study were similar to those presented by Ariyawardana et al. (19). In addition, C. albicans was the predominant species isolated $(87.5 \%)$ in OSMF patients in this study; other identified species were C. krusei and C. tropicalis (Fig. 4).

We also isolated two species of Candida at the same time in 3 of the 20 OSMF patients. Most people carry a single strain of Candida at different body sites for a long time. For instance $C$. albicans is most prevalent on the palate, tongue and gingiva. However, this study shows that a few individuals may harbor more than one strain or species of Candida at the same time. This observation suggests that several ecological niches exist in the oral cavity that harbor different Candida species. However, this occurs more commonly in hospitalized and immunocompromised patients $(14,20)$.

In this study, mouth opening was included in the assessment of clinical staging, and gutkha was most commonly chewed by these patients; gutkha is known to cause early clinical symptoms and early malignant transformation (tobacco is one component of gutkha). However, this study found no correlation between candidal carriage and gender, gutkha habit or clinical staging in these OSMF patients.

In order to proliferate in the oral cavity, yeast cells must adhere to oral surfaces; otherwise, they are washed away by salivary flows. One of the most important factors affecting the virulence of Candida species is therefore their ability to use a variety of mechanisms to anchor to a site and colonize (20). In betel quid chewers and OSMF patients, the constant chewing of betel quid increases the salivary flow rate and should lead to the loss of superficial colonization and Candida growth. In addition, the hydrophilic solvents present in betel quid have inhibitory effects and lead to a decreased oral carriage rate of Candida (17). The slaked lime content of gutkha creates an alkaline $\mathrm{pH}$ in the oral cavity; this $\mathrm{pH}$ is not favorable for Candida growth because Candida is best able to adhere to epithelial cells at an acidic $\mathrm{pH}$. All of these factors could explain the low candidal carriage found in OSMF and betel quid chewers. Our study therefore shows similar results as previous studies.

In contrast, Reichart et al. reported that the chemical constituents of betel quid have no overall effect on the oral carriage of Candida and do not preferentially affect the specific Candida species present in the oral environment. Although betel quid has some antibacterial effects, it does not affect oral Candida species (17).

Oral yeast species carry a significant risk of malignant transformation. There appears to be a statistically significance relationship between histologically determined fungal infection and epithelial dysplasia; about $21.9 \%$ of candidal infected lesions showed more severe epithelial dysplasia $(2,13)$. The possible association between
Candida species and oral neoplasia was first reported in the 1960s, and later reports suggested a link between the oral mucosal presence of C. albicans and the development of oral squamous cell carcinoma (13). Field et al. (1989), after reviewing evidence for the role of Candida in oral epithelial neoplasia, postulated that nitrosamine compounds produced by Candida species may directly, or in concert with other chemical carcinogens, activate specific protooncogenes and thus initiate the development of a malignant lesion (21).

Oral submucous fibrosis has a significant mortality rate as it is a premalignant condition and malignant transformation has been noticed in 2.3-7.6\% of cases (22). As the oral mucosa is compromised in OSMF, it can be argued that the presence of Candida may predispose the individual to candidal infection and invasion, although our results were not statistically significant.

OSMF does not regress spontaneously or on cessation of gutkha chewing. Once the disease is present, it either persists or becomes more severe with the involvement of additional areas of the oral mucosa. There is currently no successful treatment available for OSMF. Local and systemic applications of glucocorticoids and placental extracts and the intralesional injection of hyaluronidase (which breaks down the components of connective tissue) have been used for OSF therapy (23). Muzyka and Glick surmised that corticosteroids lower host resistance to Candida by suppressing both nonspecific inflammatory responses and cell-mediated immunity (24). Candida colonization that is not clinically evident may be easily overlooked, leading to ineffective treatment of the underlying lesions. It is therefore beneficial to examine the yeast cultures in the oral lesions of patients during prolonged steroid therapy. Until now very few papers have focused on the prevalence of oral Candida in OSMF patients. Therefore the present study made an attempt to observe the presence and intensity of Candida in OSMF patients.

\section{Conclusions}

A higher incidence and intensity of Candida was observed in OSMF patients when compared to healthy individuals, but these findings were within normal limits (3-47\%). The predominant species isolated was $C$. albicans. Candida may not be an etiologic factor in malignant transformation in OSMF patients. However, controversy still exists over whether betel quid chewing in OSMF inhibits or promotes the adherence and invasion of Candida. Further research with larger sample sizes is warranted to elucidate the factors that may predispose individuals with OSMF to oral candidal colonization. Phenotypic characteristics may endow certain Candida species or strains with a competitive advantage in the oral cavity. 
1. Arendorf TM, Walker DM. The prevalence and intraoral distribution of Candida albicans in man. Arch Oral Biol 1980;15:1-10.

2. Sitheeque MAM, Samaranayake LP. Chronic hyperplastic candidosis/candidiasis. Crit Rev Oral Biol Med 2003;4:253-67.

3. Samaranayake LP. Host factors and oral candidosis. In: Samaranayake LP, McFarlane TW (eds). Oral Candidosis. London: Wright; 1990.

4. Reichart PA, Samaranayake LP, Philipsen HP. Pathology and clinical correlates in oral candidiasis and its variants: a review. Oral Dis 2000;6:85-91.

5. Coleman DC, Bennett DE, Sullivan D, Gallagher PJ, Henman MC, Stanley DB. Oral Candida in HIV infection and AIDS: new perspective/new approaches. Crit Rev Microbiol 1993; 19:61-82.

6. Cannon RD, Holmes AR, Mason AB. Oral Candida: clearance, colonization, or candidiasis? J Dent Res 1995;74:1152-61.

7. Nair U, Bartsch H, Nair J. Alert for an epidemic of oral cancer due to use of the betel quid substitutes gutkha and pan masala: a review of agents and causative mechanisms. Mutagenesis 2004;19:251-62.

8. Pillai R, Balaram P, Reddiar KS. Pathogenesis of oral submucous fibrosis. Relationship to risk factors associated with oral cancer. Cancer 1992;69:2011-20.

9. Ariyawardana GA, Panagoda J, Fernando HN, Ellepola ANB, Tilakaratne WM, Samaranayake LP. Oral submucous fibrosis and oral yeast carriage - a case control study in Sri Lankan patients. Mycoses 2007;50:1 16-20.

10. Ranganathan K, Gauri Mishra. An overview of classification schemes for oral submucous fibrosis. JOMFP 2006;10:55-8.

11. Samaranayake LP, MacFarlane TW, Lamey P-J, Ferguson MM. A comparison of oral rinse and imprint sampling techniques for the detection of yeast, coliform and Staphylococcus aureus carriage in the oral cavity. J Oral Pathol 1986;15:251-4.

12. Meurman JH, Siikala E, Richardson M, Rautemaa R. Non-Candida albicans Candida yeasts of the oral cavity. In: Mendez-Vilas A (ed.). Communicating current research and educational topics and trends in applied microbiology. Microbiology book series. Badajoz: Formatex; 2007.

13. McCulough M, Jaber M, Barrett AW, Bain L, Speight P, Porter SR. Oral yeast carriage correlates with presence of oral epithelial dysplasia. Oral Oncol 2002;38:391-3.

14. Krogh P, Holmstrup P, Thorn JJ, Vedtofte P, Pindborg JJ. Yeast species and biotypes associated with oral leukoplakia and lichen planus. Oral Surg Oral Med Oral Pathol 1987;63: 48-54.

15. Kumar RS, Ganvir SM, Hazarey VK. Candida and calcofluor white: Study in precancer and cancer. JOMFP 2009; 13:2-8.

16. Jainkittivong A, Kuvatanasuchati MJ, Pipattanagovit P, Sinheng. Candida in oral lichen planus patients undergoing topical steroid therapy. Oral Surg Oral Med Oral Pathol Oral Radiol Endod 2007; 104:61-6.

17. Reichart PA, Schmidtberg W, Samaranayake LP, Scheifele C. Betel quid associated oral lesions and oral Candida species in a female Cambodian cohort. J Oral Pathol Med 2002;31:468-72.

18. Reichart PA, Khongkhunthian P, Samaranayake LP, Yau J, Patanaporn V, Scheifele C. Oral Candida species and betel quid-associated oral lesions in Padaung women of northern Thailand. Mycoses 2005;48:132-6.

19. Ariyawardana GA, Panagoda J, Fernando HN, Ellepola ANB, Tilakaratne WM, Samaranayake LP. Oral submucous fibrosis and oral yeast carriage - a case control study in Sri Lankan patients. Mycoses 2007;50:1 16-20.

20. Henriques M, Azeredo J, Oliveira R. Candida species adhesion to oral epithelium: factors involved and experimental methodology used. Crit Rev Microbiol 2006;32:217-26.

21. Field EA, Field JK, Martin MV. Does Candida have a role in oral epithelial neoplasia? J Med Vet Mycol 1989;27:277-94.

22. Ho P, Chen P, Warnakulasuriya $S$, Shieh T, Chen Y, Huang I. Malignant transformation of oral potentially malignant disorders in males: a retrospective cohort study. BMC Cancer 2009;9:260-7.

23. Lai DR, Chen HR, Lin LM, Huang YL, Tsai CC. Clinical evaluation of different treatment methods for oral submucous fibrosis. A 10 -year experience with 150 cases. J Oral Pathol Med 1995;24:402-6.

24. Muzyka BC, Glick M. A review of oral fungal infections and appropriate therapy. J Am Dent Assoc 1995;126:63-72. 